\title{
Say no to boycott of ADS conference
}

Sir - Your columns have included speculation that the International AIDS Society might countenance a boycott of the International Conference on AIDS to be held in Durban, South Africa in July 2000 (Nature 398, 8; 1999). This issue has arisen because of the refusal of the South African government to routinely offer antiretroviral drugs (ARVs) to HIV-infected pregnant women, in spite of the fact that short courses of ARVs towards the end of pregnancy can reduce the likelihood of HIV transmission to infants by up to 75 per cent.

We are firmly opposed to a boycott, which would only harm the interests of those whom the well-intentioned proponents of this idea would seek to serve.

The South African government has been accused of "the murder of babies" and of having a policy that many would have considered racist, had it been implemented by the apartheid regime. The government insists that the cost-benefit of providing ARVs to HIV-positive pregnant women should be demonstrated before any change in policy is made. But critics argue that these government studies have already been done and show that the expenses associated with the purchase of drugs, formula and clean water, and the need to care for the uninfected orphans, will be surpassed or at least equalled by the costs of providing medical treatment to the many thousands of babies who will be born with preventable HIV disease. An estimated 600,000 HIVinfected infants are born worldwide each year, 60,000 of them in South Africa.

The biennial International Conference on AIDS gains more media coverage than any other medical or scientific conference. The media barrage probably does more to promote HIV awareness and prevention than the efforts of the scientists who present their work at the meeting. We believe that the publicity surrounding the Durban conference has the potential to translate into millions fewer new cases of HIV infection in developing countries.

Until now, South African government policy on ARVs has not received much international media scrutiny. This will change during the weeks before the conference. The government may find that a well-attended conference, with its media presence, creates more pressure to change policy on drugs for HIV-infected pregnant women than a boycott ever would have.

Mark A. Wainberg

(President)

International AIDS Society, McGill University AIDS Centre, Jewish General Hospital, 3755 Chemin Côte-Ste-Catherine, Montreal, Quebec H3T 1E2, Canada

\section{Take the best from both}

\section{patents systems}

Sir - As a patent lawyer, I read with interest your report on the European efforts to persuade the United States to switch to the first-to-file system for determining priority on patentable inventions ${ }^{1}$. While the firstto-file system appears to be simpler, and the norm outside the United States, it would be a mistake to abandon the American system based on 'first to invent'.

The apportionment of credit for inventions is not a mere intellectual concern because bonuses and promotions are often tied to productivity measured by patentable research. But many researchers are unable to voice their claims at the time of filing a patent because others are claiming more credit than is due to them. Reasons for such reticence include job insecurity, change in employment, immigration concerns or just the ordinary politics that accompanies all human activities.

Unlike a scientific research paper, a patent issued in the United States can be invalidated for improper naming of inventors, as measured by the conception of the invention. This includes omission and improper inclusion of inventors. Thus, the American system provides true inventors with a safeguard that can be invoked if they provide reasonable evidence of their activities. Correction of inventorship is a common hurdle faced by European patent applications filed in the United States, owing to lax standards in assigning credit elsewhere. Interestingly, in the same issue of Nature Michael J. Larkin ${ }^{2}$ reports that established UK molecular biologists published an average of only one paper every 3.8 years in their early careers. The US system is not perfect but it does address a problem that is mostly just debated elsewhere.

A potential compromise would be to measure priority of the patent itself by the first-to-file system but also require the naming of the inventors. Inventors would be able to appeal if their names were excluded. This would retain the threat of invalidation of tainted patents while incorporating the efficiencies of the first-tofile system.

Rattan Nath

1830 Euclid Avenue, Berwyn, Illinois 60402, USA

1. Masood, E. Nature 397, 457 (1999).

2. Larkin, M. J. Nature 397, 467 (1999).

\section{On the trail of the prolificDrPath}

Sir — While using an electronic abstracting service I was surprised to see an additional author on one paper. This author, D. Phil, had a good publication record in a variety of fields -76 papers over the past 18 years.

I also noted reasonable publication rates in medical research for M. R. C. Path (48), B. Chir (31) and F. R. C. Path (22). The Paths may be related as they have published jointly on four occasions. But F. R. C. Anaes (7), M. I. Biol (5) and C. Chem (4) do not seem to have been so productive.
Perhaps Janne Kotiaho's concerns about mis-citation should not be limited to articles originating in non-English speaking countries (Nature 398, 19; 1999). And perhaps citations should not be used uncritically for any serious purpose - at least until abstracting services become more accurate, and discover the tradition, particularly in medical journals, of giving degrees and professional qualifications after authors' names.

Nigel L. Brown

School of Biological Sciences, University of

Birmingham, Edgbaston, Birmingham B15 2TT, UK

\section{Going cold on ‘snowball} Earth' theory

Sir — Paul Hoffman and Adam Maloof ${ }^{1}$, in discussing the paper by D. M. Williams et $a l^{2}$, misconstrue the large-obliquity hypothesis for low-latitude glaciation near sea level during the Proterozoic ${ }^{3}$ and overlook relevant geological evidence.

Seasonality would be greatly amplified globally with a large obliquity $\left(>54^{\circ}\right)$. The solsticial climate would be severe in high latitudes but more benign near the Equator, where mean annual insolation would be minimal and where substantial snowfall could occur. The net accumulation of solsticial snow through successive equinoxes, necessary for low-latitude glaciation, would be aided by the high albedo of snow and ice. Importantly, Neoproterozoic glaciogenic deposits in Australia that formed near the palaeo- 
equator ${ }^{4}$ contain seasonal freeze-thaw wedge structures in permafrost regolith that indicate marked seasonal changes of temperature ${ }^{3,4}$.

The 'snowball Earth' hypothesis for lowlatitude glaciation ${ }^{5}$ is difficult to simulate ${ }^{6,7}$ and conflicts with geological evidence. The late Neoproterozoic stratigraphic record ${ }^{8}$ shows no sign of the drastic lowering of sea level that would accompany global glaciation. Moreover, seasonal freeze-thaw structures could not form near the Equator on a snowball Earth because the very low global temperatures would inhibit seasonal variation $^{9}$.

\section{George E. Williams}

Department of Geology and Geophysics,

University of Adelaide, SA 5005, Australia

1. Hoffman, P. F. \& Maloof, A. C. Nature 397, 384 (1999).

2. Williams, D. M. et al. Nature 396, 453-455 (1998).

3. Williams, G. E. Earth Sci. Rev. 34, 1-45 (1993).

4. Schmidt, P. W. \& Williams, G. E. Earth Planet. Sci. Lett. 134, 107-124 (1995).

5. Hoffman, P. F. et al. Science 281, 1342-1346 (1998).

6. Crowley, T. J. \& Baum, S. K. J. Geophys. Res. 98, 16723-16732 (1993)

7. Walsh, K. J. \& Sellers, W. D. Global Planet. Change 8, 219-230 (1993)

8. Preiss, W. V. Geol. Surv. S. Aust. Bull. 53, 438 (1987).

9. Sellers, W. D. Palaeogeogr., Palaeoclimatol., Palaeoecol. 82 217-224 (1990).

\section{Denmark lacks coherent policy on basic research}

Sir - Recent months have seen a lively, and at times bitter, debate in the Danish media on the future direction of scientific research. Much has been made by the government of the need to shift towards more applied research to maximize the short-term benefits of public investment. However, we would suggest that more critical problems exist that must be addressed immediately to ensure the longterm health of Danish science. Chief among these are a poorly funded and misdirected policy on basic research funding, and conditions of employment that restrict the research opportunities of young scientists.

Danish science is moderately well funded ${ }^{1}$. We have modern facilities, an excellent level of technical support and a buoyant biotechnology sector ${ }^{2}$. What is sorely lacking is a coherent policy on the funding and nurturing of basic research. Entry-level appointments (assistant professor) have a heavy teaching load and no support for scientific staff. Young scientists cannot improve their situation by writing grant applications, since the funding available to the research councils allows little, if any, support for salary components. Such restrictions are making assistant professorships increasingly unattractive, with limited long-term prospects. This situation is only alleviated by the benefaction of senior scientists and charitable foundations, and occasional directives in selected areas which allow young scientists to develop independent research.

Further obstacles exist in the recruitment process: new positions are often focused on narrow research areas and only advertised locally (in Danish). Recent well-intentioned legislative changes have not fully addressed these problems.

Such an inflexible system (which often obliges scientists to spend their entire career in the same institute) is ill-equipped to adapt to the rapid development of new areas in basic research. The only surprise is that Danish science has remained so competitive for so long. How long this will continue to be the case is unclear when there is little to attract young scientists. Without a competitive basic research component, the ability to foster novel applied research (so beloved of the present government) will be severely eroded.

Similar criticisms have been levelled at Sweden. In its case at least some of these criticisms are now being taken to heart, as can be seen by the establishment of openly competitive, well funded, junior faculty positions at the new Centre for Molecular Medicine in Umea. We hope that similar initiatives will be taken in Denmark.

Michael Ibba, Thomas Bentin

Centre for Biomolecular Recognition, Institute of Medical Biochemistry and Genetics, Panum Institute, Copenhagen University, 2200 Copenhagen N, Denmark

1. May, R. M. Science 281, 49-51 (1998).

2. Horton, B. Nature 395, 412-413 (1998).

\section{Green revolution} still too green

Sir - L. E. Drinkwater et al. ${ }^{1}$ report promising isolated studies on environmental quality and productivity in crop production. But these studies should not be used to discredit high-yield crop production technologies globally.

We do not dispute David Tilman's call, in his News and Views article ${ }^{2}$ accompanying the paper by Drinkwater $e t$ al., for a greener agriculture based on ecological principles. But we do not think that as things stand we have the ability to cope with the probable doubling in global food demand in the twenty-first century with only organic nutrient inputs.

The organic nitrogen production schemes investigated by Drinkwater et al. used essentially twice the land area of their 'conventional' system to produce equivalent amounts of grain. But the best arable land is already used for crop production. Therefore expansion of agriculture to produce the required organic nitrogen would necessitate use of marginal land or further encroachment on natural ecosystems, resulting in soil degradation and loss of biological diversity.

Additionally, agronomic technology has advanced considerably beyond the 'conventional' practices used by Drinkwater et al. In industrialized countries, the mould-board plough has been largely replaced by no-till and conservation tillage practices. Single applications of fertilizer are being replaced by multiple applications with amounts and timing matched to crop requirements. These practices result in improved soil conservation and quality; greater efficiency in fertilizer use; higher and more stable yields; and they also minimize the land area required for crop production.

Progress towards a 'greener' agriculture will come from continued improvements in modern high-yield crop-production methods combined with sophisticated use of both inorganic and organic nutrient sources, water, crop germplasm, pest management and beneficial organisms. Thomas R. Sinclair ${ }^{\star}$, Kenneth G. Cassman $\dagger$ ${ }^{*}$ USDA-ARS, Agronomy Department, University of Florida, Gainesville, Florida 32611-0965, USA $\dagger$ Department of Agronomy, University of Nebraska, Lincoln, Nebraska 68583-0915, USA

1. Drinkwater, L. E. et al. Nature 396, 262-265 (1998).

2. Tilman, D. Nature 396, 211-212 (1998).

\section{Fertile grounds for a lively debate}

Sir - I am not surprised that Hermann Bondi ${ }^{1}$ was puzzled by my correspondence with Roger Short ${ }^{2,3}$, which concerned the relative importance of fertility and agriculture in the population explosion.

I myself was puzzled by Short's response, because I was not arguing that fertility is influenced by nutrition; in fact I had been naively unaware that this is the subject of a lively controversy.

I simply meant that an increase in fertility (from whatever cause) could not by itself have resulted in population growth because the additional babies would have starved. Without the agricultural advances of this century, the world population would not now be approaching six billion, no matter what the fertility rates were.

\section{Stephen G. Warren}

Department of Atmospheric Sciences, University of Washington, Seattle, Washington 98195-1640, USA
1. Bondi, H. Nature 397, 644 (1999).
2. Warren, S. G. Nature 397, 101 (1999).
3. Short, R. Nature 397, 101 (1999). 